\title{
International Myeloma Working Group
}

National Cancer Institute

\section{Source}

National Cancer Institute. International Myeloma Working Group. NCI Thesaurus. Code C153239.

A working group established to conduct basic, clinical and translational research in a collaborative manner to improve outcomes in myeloma and to provide scientifically valid and critically appraised consensus opinions on the diagnosis and treatment of myeloma and related disorders. 